Article

\title{
Pathways to Coastal Resiliency: The Adaptive Gradients Framework
}

\author{
Elisabeth M. Hamin ${ }^{1}$, , Yaser Abunnasr ${ }^{2}$, Max Roman Dilthey ${ }^{1}$, Pamela K. Judge ${ }^{3}$ (D), \\ Melissa A. Kenney 4 (i), Paul Kirshen ${ }^{5}$, Thomas C. Sheahan ${ }^{6}$, Don J. DeGroot ${ }^{7}$, Robert L. Ryan ${ }^{1}$, \\ Brain G. McAdoo ${ }^{8}$, Leonard Nurse ${ }^{9}$, Jane A. Buxton ${ }^{1}$, Ariana E. Sutton-Grier ${ }^{4}$ (D), \\ Elizabeth A. Albright ${ }^{10}$, Marielos Arlen Marin ${ }^{1}$ and Rebecca Fricke ${ }^{1}$
}

1 Department of Landscape Architecture and Regional Planning, University of Massachusetts Amherst, Amherst, MA 01003, USA; mdilthey@gmail.com (M.R.D.); rlryan@umass.edu (R.L.R.); jane.a.buxton@gmail.com (J.A.B.); marielosmari@umass.edu (M.A.M.); rfricke@umass.edu (R.F.)

2 Department of Landscape Design and Ecosystem Management, American University of Beirut, P.O. Box 11-0236 Beirut, Lebanon; ya20@aub.edu.lb

3 School of Engineering, Computing, and Construction Management, Roger Williams University, Bristol, RI 02809, USA; pjudge@rwu.edu

4 Earth System Science Interdisciplinary Center and Cooperative Institute for Climate and Satellites-Maryland, University of Maryland, College Park, MD 20740, USA; kenney@umd.edu (M.A.K.); ariana.suttongrier@gmail.com (A.E.S.-G.)

5 School for the Environment, University of Massachusetts Boston, Boston, MA 02125, USA; paul.kirshen@umb.edu

6 College of Engineering, Northeastern University, Boston, MA 02115, USA; tsheahan@northeastern.edu

7 Department of Civil and Environmental Engineering, University of Massachusetts Amherst, Amherst, MA 01003, USA; degroot@umass.edu

8 Environmental Studies, Yale-NUS College, Singapore 138610, Singapore; brian.mcadoo@yale-nus.edu.sg

9 Centre for Resources Management and Environmental Studies, University of West Indies at Cave Hill, Cave Hill BB11000, Barbados; leonard.nurse@cavehill.uwi.edu

10 Nicholas School of the Environment, Duke University, Durham, NC 27708, USA; elizabeth.albright@duke.edu

* Correspondence: emhamin@umass.edu; Tel.: +1-413-336-7755

Received: 3 June 2018; Accepted: 19 July 2018; Published: 26 July 2018

Abstract: Current and future climate-related coastal impacts such as catastrophic and repetitive flooding, hurricane intensity, and sea level rise necessitate a new approach to developing and managing coastal infrastructure. Traditional "hard" or "grey" engineering solutions are proving both expensive and inflexible in the face of a rapidly changing coastal environment. Hybrid solutions that incorporate natural, nature-based, structural, and non-structural features may better achieve a broad set of goals such as ecological enhancement, long-term adaptation, and social benefits, but broad consideration and uptake of these approaches has been slow. One barrier to the widespread implementation of hybrid solutions is the lack of a relatively quick but holistic evaluation framework that places these broader environmental and societal goals on equal footing with the more traditional goal of exposure reduction. To respond to this need, the Adaptive Gradients Framework was developed and pilot-tested as a qualitative, flexible, and collaborative process guide for organizations to understand, evaluate, and potentially select more diverse kinds of infrastructural responses. These responses would ideally include natural, nature-based, and regulatory/cultural approaches, as well as hybrid designs combining multiple approaches. It enables rapid expert review of project designs based on eight metrics called "gradients", which include exposure reduction, cost efficiency, institutional capacity, ecological enhancement, adaptation over time, greenhouse gas reduction, participatory process, and social benefits. The framework was conceptualized and developed in three phases: relevant factors and barriers were collected from practitioners and experts by survey; these factors were ranked by importance and used to develop the initial framework; several case studies 
were iteratively evaluated using this technique; and the framework was finalized for implementation. The article presents the framework and a pilot test of its application, along with resources that would enable wider application of the framework by practitioners and theorists.

Keywords: green infrastructure; coastal resilience; coastal restoration; social-ecological systems; co-benefits; climate adaptation

\section{Introduction}

The many and varied recent coastal disasters highlight the importance of creating more resilient coastal areas. Climate change is exacerbating the impact of these events, along with the increased concentration of people and assets in urban areas. Some impacted areas will be abandoned through retreat. Others will be rebuilt, and new lands will continue to be urbanized, bringing opportunities to re-envision infrastructure designs. The stakes are high—one study found that protecting seaports across the globe from climate change will require about 49 million metric tons of concrete alone [1], if traditional construction methods are used; globally, 271 million people are at risk from coastal flooding, and that number will rise to 345 million by 2050 [2]. The risks for small island developing states are particularly high [3,4], as 2017 hurricanes Irma and Maria in the Caribbean have shown. All of these threats and concerns due to climate change are leading communities to re-consider approaches for coastal protection. More socially and ecologically beneficial coastal resiliency actions are necessary given the continuing build-up of coastlines and the interdependence of ecosystems and social-ecological resilience [5].

Recent years have seen significant advances in developing a wider range of options for coastal restoration and protection [6], and projects now include approaches that go beyond traditional infrastructure. The range of choices includes natural, nature-based, and non-structural measures such as living shorelines [7], revised building codes, zoning, and community disaster preparedness [8]. Here, we define hybrid designs as those that include non-structural interventions such as zoning changes and local capacity building alongside green and grey approaches (see Figure 1). Current research suggests that hybrid projects may provide the greatest potential for improving resilience to climate impacts [9-12], with different components working together to create mutually supportive conditions. When compared to traditional methods, this broader portfolio of coastal adaptation options can achieve social and environmental objectives alongside exposure reduction, and may achieve change across multiple criterion [13,14], as recommended in the Intergovernmental Panel on Climate Change (IPCC) Fifth Assessment Report [15].

Despite the strong research into theory and design innovations in coastal adaptation, adoption of hybrid projects has been slow, albeit increasing [16]. One of the challenges of hybrid approaches is that they require holistic consideration of biophysical, engineering, economic, legal and sociocultural components. These projects bridge across discipline-specific practices and terminology, posing logistical and methodological challenges for policy-makers and designers [17]. Nordenson and Seavitt [18] find that coastal land use decisions and planning would be greatly improved with a clear identification and articulation of a broad potential range of goals such as ecosystem support and co-benefits for impacted communities. An interdisciplinary approach that utilizes a diversity of expertise, experience, and perspectives across multiple stakeholders from the practitioner, academic, and public domains would assist in overcoming this barrier. 


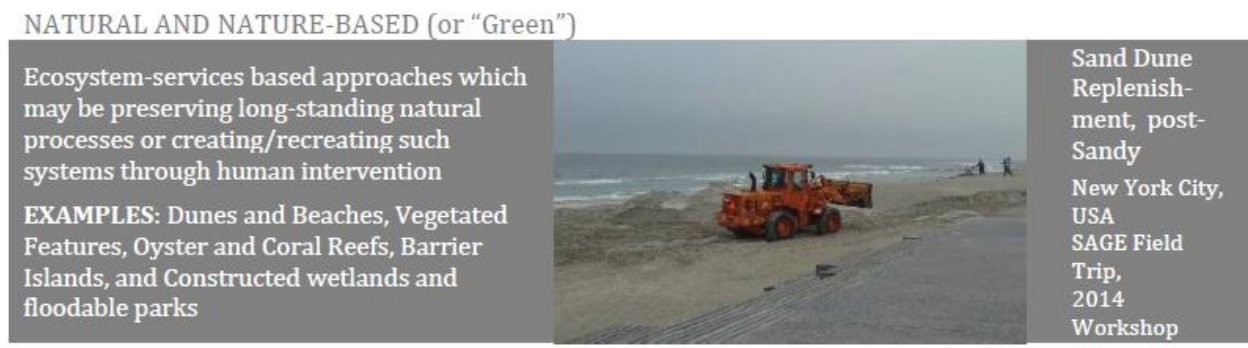

STRUCTURAL (or "Grey")

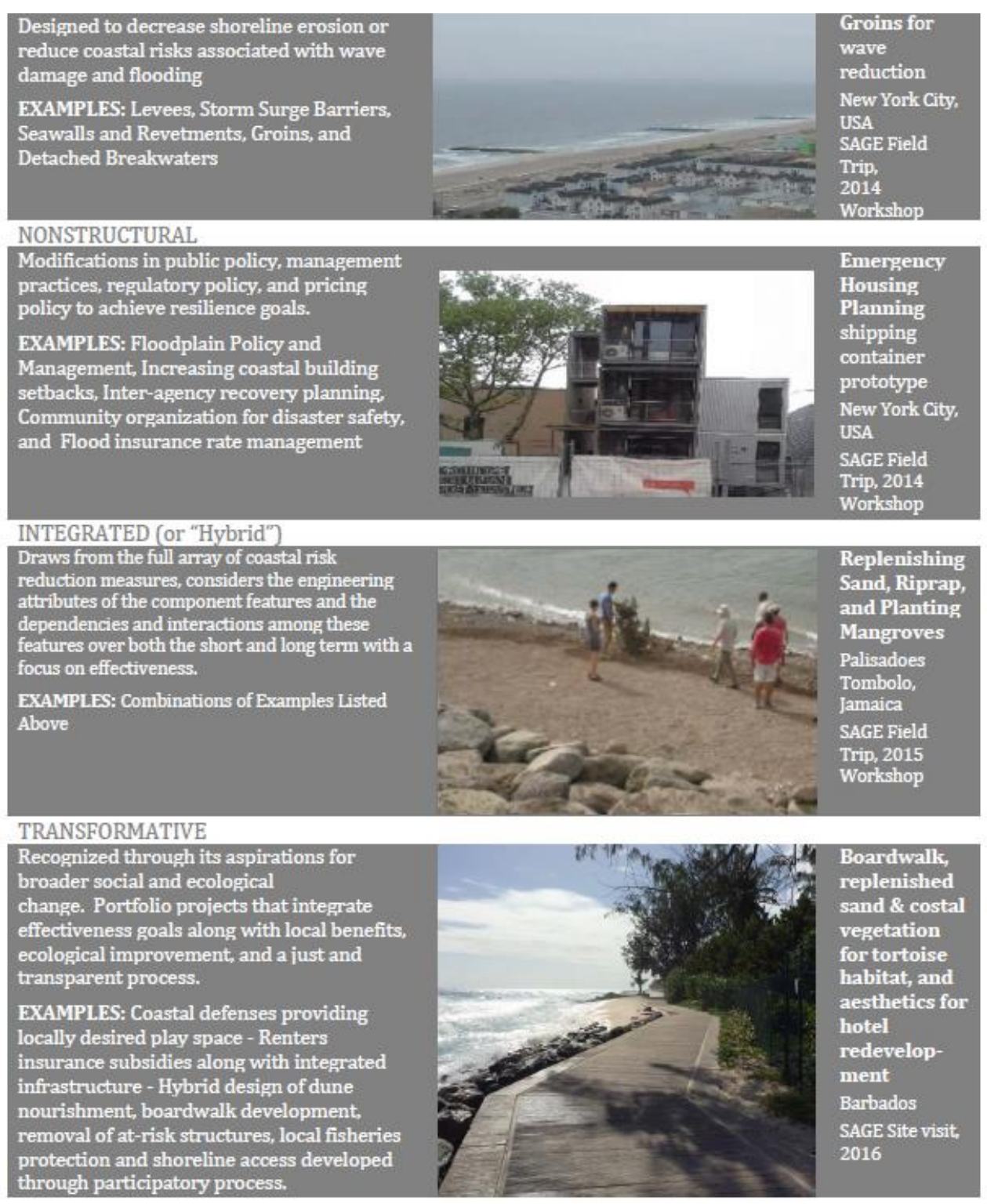

Figure 1. Defining infrastructure and intervention types. This figure synthesizes language used across several disciplines around types of coastal resilience measures, particularly engineering, policy, and landscape architecture, to ensure interdisciplinary accuracy in conversation. The first panel presents nature-based engineering and ecosystem approaches; the second panel focuses on traditional built forms such as seawalls; the third panel identifies alternative approaches that focus on regulations and culture to change coastal resiliency; and the final panel defines the integration of these three as fully hybrid approaches. Sources: [8,19,20]. Photos: SAGE Workshop Field Trips and site visits; 2014-2016. Photo credit: Rebecca Fricke. 
To address this need, a network of North American and Caribbean researchers, the Sustainable Adaptive Gradients in the coastal Environment (SAGE) network, developed the Adaptive Gradients Framework as a means of improving the visibility and facilitating the discussion of multiple goals for coastal systems projects, including social, ecological, and technical aspects. In this article, we detail this Adaptive Gradients framework and provide a case study, demonstrating how this Framework can highlight the range of goals these more complex, hybrid projects may achieve.

\subsection{Gradients}

Many, if not most, natural processes exist along a continuum defined by fairly constant (but sometimes steep) gradients. The concept of a gradient informs the design of the Adaptive Gradients Framework, by suggesting the consideration of different aspects of coastal resiliency along sliding scales. Gradients describe the range of conditions in a particular system, placed along some scale (e.g., temporal, spatial, biofunctional, etc.) that will allow comparison across cases [21]. For instance, climate tends to vary along a longitudinal gradient from hot, moist equatorial regions to cold, dry polar regions, and historically, biological systems are fairly well adapted to the temperatures and weather patterns along this gradient. However, this adaptation is being challenged by climate change-induced changes, such as droughts and extreme weather events. Many regional socio-economic characteristics can be conceptualized along gradients as well, such as population density, income inequality, or population health. However, not all characteristics are gradual. Physical factors for hazard risk can change quite abruptly, such as types of offshore soils, and social characteristics like ethnic self-identification can be quite distinct in adjacent regions. This gradient concept informs the intellectual foundation of the Adaptive Gradients framework.

\subsection{Current Frameworks and Barriers to Hybrid or Greener Designs}

The IPCC frameworks on risk provide a baseline language for resilience planning [22]. The IPCC finds that disaster risk is based on physical conditions amplified by anthropogenic contributions to climate change, using socially framed impact parameters. More precisely, risk from climate change is defined as a function of hazards, exposure and vulnerability. Hazard is the climate-related physical event, including storms, droughts, landslides, increased disease vectors, etc., with climate change as an exacerbating factor. Vulnerability is defined as the level of susceptibility to harm, while exposure is the people, assets, and ecosystems that may be affected by a hazard event. Applying these to a hurricane yields this basic form of analysis: what is the seriousness of the hurricane (the hazard); how many people, which ecosystems, and what value or social importance of buildings and other assets will likely be affected (the exposure); and how well the systems and people will be likely to recover (the vulnerability). At the local level, projects may reduce hazard through such actions as reducing wave height and energy. They may also ameliorate exposure by moving or protecting the people, species, and ecological, social, and economic resources in at-risk areas. This reduces vulnerability [23]. Other definitions of risk take a more probabilistic approach, with risk being defined as the probability of an event (the hazard) times the consequences (the vulnerability) [24,25].

Structural/grey infrastructure interventions, as the de facto baseline for many coastal projects, are often well suited to addressing exposure. These traditional grey approaches may, however, also encourage maladaptation, in which projects intended to improve resilience also increase greenhouse gas emissions, burden the most vulnerable, or create other social issues while pursuing the stated mission [26]. Particular organizational norms may strongly orient to structural interventions, such as the use of benefit-cost analysis for Environmental Impact Statement (EIS) by the U.S. Environmental Protection Agency (EPA) and/or structured decision-making practices used by the U.S. Geological Survey for environmental management $[27,28]$ or the US Army Corps of Engineers. Even when agencies seek to expand beyond these traditional measures (see, e.g., [16]), they may be challenged by the complexity of social and environmental dimensions of resilience such as the technical challenge of an uncertain climate future [29], and difficulty in effectively addressing aspects of justice 
and public participation in decision-making under complexity [30]. As climate change impacts increase across the globe, well-established prescriptive approaches for identifying initial or preferred protection solutions [31] have been criticized for being too restrictive, often failing to encompass socioeconomic realities and plurality in stakeholder values and objectives [32]. This leaves prescriptive, unidimensional approaches inadequate for long-term resilience [33].

Among the barriers for uptake of infrastructure innovations is that most institutions experience path dependence, which Mathews et al. [34] define as "situations where institutions become used to responding to specific issues and are consequently reluctant to respond to new imperatives when they manifest". Minor incremental change is easier than major shifts in organizational culture. Deeply held social norms such as a preference for knowledge stability (comfort in knowing what we know, rather than the challenge of admitting what we do not know) and predictability may work against the kinds of innovative and novel practices required for climate change adaptation planning and policies [35]. For green infrastructure, path dependence tends to lead to adding multiple goals as secondary considerations within existing planning frameworks, rather than undertaking more substantive change [34]. Path dependence exists at the project scale as well. Once design alternatives are identified and significant dollars are spent on modeling those alternatives, an organization is less likely to consider significant changes to a design. To overcome these issues, it may be helpful to influence processes early in the development of a project, before significant resources (financial, as well as institutional and reputational) are invested in a particular, and likely more traditional, approach.

Beyond the challenge of path dependence, a range of other barriers to the adoption of more innovative resilient infrastructure has been identified. In adaptation more generally, identified barriers can be categorized as a lack of leadership, lack of resources, challenges in communication and information, and conflicting deeply held values and beliefs [36]. Lack of information is a critical problem, as planners and decision-makers are often asked to implement adaptation measures without adequate information about local-scale impacts, vulnerabilities, or the long-term consequences of an intervention [37]. This is particularly challenging in situations which lack officially accepted projections or institutional mandates for using projections that do exist [38,39]. The breadth of disciplinary knowledge required for hybrid designs is another informational challenge; a decision framework that supports hybrid designs will need to supplement typical engineering expertise with ecological, social, land use, policy and participatory process knowledge.

An important response to these challenges has been to complement traditional engineering effectiveness and benefit-cost analysis with a focus on the benefits of projects that go beyond their contributions to exposure reduction, central as that remains (see, e.g., [40]). The term co-benefits is defined in some contexts as complementarity between mitigation and adaptation [41]; here, we use a broader definition that describes how project outcomes achieve locally desired goals outside of primary hazard reduction, such as health benefits from particulate reduction through urban greening, provision of locally desired public space, or restoration of local fisheries through erosion control [42]. A just distribution of benefits is an important theme in research and practice of climate adaptation because less-resourced communities tend to experience greater environmental risk [43,44]. Given the challenges and conflicting priorities facing local governments, it can be politically and practically helpful to publicly and clearly define these anticipated co-benefits [45].

Based on the current literature, infrastructure planning and evaluation should incorporate concepts of resilience and vulnerability [46-48], address climate adaptation [36,49], establish indicator systems [50], and utilize monitoring and assessment as integral to the project [51]. A more inclusive process may help communities make better infrastructure decisions [52]. It is also good practice to include local knowledge of biophysical, socio-economic, and community components of resilient infrastructure, at both local and regional scales [53]. This local knowledge helps communities find solutions that work well for their particular needs.

Research finds that generalizable approaches to project assessment may be effective and appropriate [54]. While theory is well developed, the applications of theory in practice is 
under-represented in academic literature [37]. Despite a portfolio of adaptation measures to choose from, planners may feel left without the resources necessary to confidently make decisions, particularly for innovative and complex projects. Based on the literature above, as well as perspectives developed through the process described in the section below, we believe that a structured facilitation tool for the development of resilient infrastructure should be used early in the decision process in order to clearly identify co-benefits, integrate a range of disciplines, facilitate a range of technical and social objectives, and promote a transparent process with the potential for high levels of stakeholder participation. These observations underlie the Adaptive Gradients Framework that is proposed in this study.

\section{Methods}

These findings were reached through a collaborative four-year process undertaken by the SAGE network. SAGE is an NSF-funded network of thirty academics and practitioners across the domains of engineering, ecology, and social science, and includes representation from the US Northeast and the Caribbean, with several members from Europe. The project's webpage is http:/ / www.resilientinfrastructure.org, where details of our process and Supplementary Materials identified at the end of this paper can be found. The goal of the network was to enable cross-disciplinary and cross-geographic learning, with the particular goal of encouraging the adoption of greener, more resilient, and more just infrastructure practices. Early meetings focused on identifying barriers to the uptake of green infrastructure. A key problem that members identified was the lack of a holistic way to evaluate projects, one which would directly recognize a wider range of potential project goals early in project design. Such an approach could be most useful after initial project scoping and idea development but before issuing a full Request for Proposals, so that the RFP criteria can identify broader project goals and opportunities. This evaluation is straightforward enough to be easily explained to decision-makers and politicians, and quick and inexpensive enough to be done in less-resourced communities and countries as well as more developed ones.

To be systematic about responding to the need for more holistic infrastructure evaluation, the SAGE network undertook a holistic, collaborative, iterative theory-building research project, and began building a case study data bank (see Figure 2). The first phase began in 2014 with an online survey asking SAGE network participants from the US and Caribbean $(n=28)$ to identify the most important factors for enabling greener infrastructure. Survey participants included social scientists, civil engineers, ecologists, and policy experts in both public and private sectors, including NGOs, planning organizations, universities, and government, representing the breadth of the SAGE research network (see acknowledgements section for a list of network members). Survey participants were deliberately selected to ensure that the foundational data for the framework was representative of an interdisciplinary and holistic perspective.

All subjects gave their informed consent for inclusion before they participated in the study. The study was conducted in accordance with the Declaration of Helsinki, and the protocol was approved by the Ethics Committee of the University of Massachusetts, Amherst (2013-1734). The survey asked research participants two overarching questions:

- What are the most important factors that should, or do, influence decisions regarding particular types of coastal infrastructure will be chosen for a particular site?

- What are the greatest barriers to using 'greener' types of infrastructure choices?

Results for this first research phase were inductively coded, categorized, and re-checked with respondents at a following workshop to assure categorization was considered valid. A wide range of barriers and factors were identified.

For phase 2 of the research, a second survey was sent to network participants asking them to prioritize the factors they thought were most important to assess coastal infrastructure projects. The top factors that influence the choice of coastal infrastructure identified in this phase were (in alphabetical order): ethical and policy fitness, including whether the project could be managed by the entities, and 
whether it achieved justice goals; financial effectiveness; whether there was sufficient information about an intervention type to make decisions; fit to local community and social goals; and combined technical and ecological fitness. In surveys one and two, short answer responses included nuanced explanation. When respondents chose information as a key barrier, for instance, they discussed it in three ways-whether there was sufficient information to evaluate a project, whether the public would understand it, and how the project dealt with uncertainty. Survey findings were discussed at SAGE workshops and site visits in 2014, 2015 and 2017, with local and national decision-makers in the US Northeast, Jamaica, and Barbados, respectively.

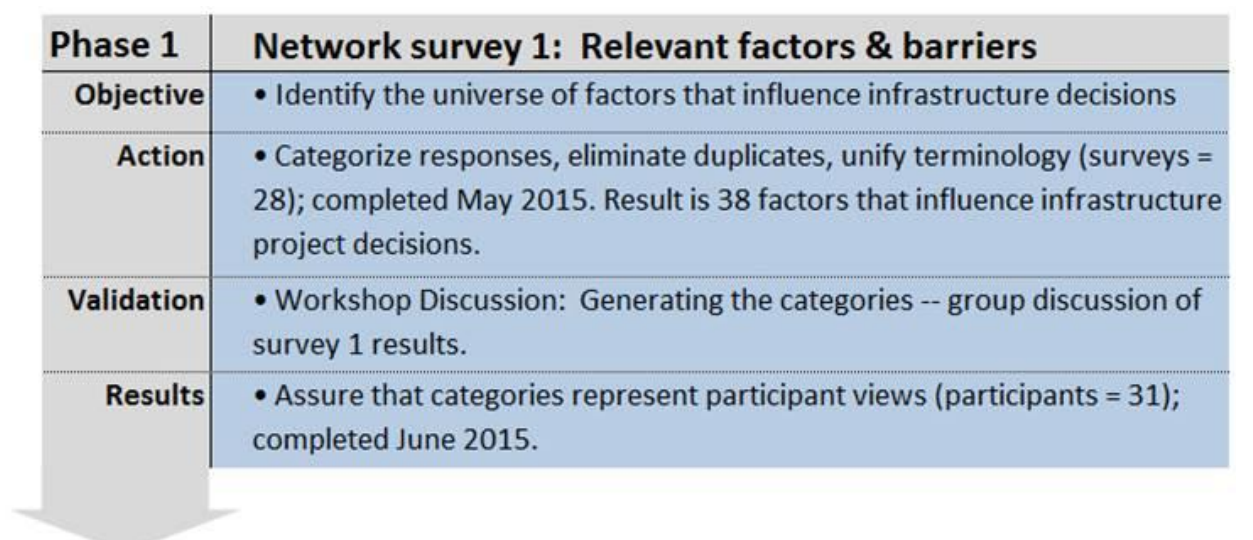

\begin{tabular}{r|l}
\hline Phase 2 & Network survey 2: Ranking the factors \\
\hline Objective & $\begin{array}{l}\text { - Identify the most important factors that influence infrastructure } \\
\text { decisions; use this to develop initial gradients }\end{array}$ \\
\hline Action & $\begin{array}{l}\text { - Retain items selected by at least } 50 \% \text { of experts and categorize; } \\
\text { completed August 2015. Results in } 5 \text { factors / gradients. }\end{array}$ \\
\hline Validation & $\begin{array}{l}\text { - Workshop Discussion: Testing the categories - group discussion of } \\
\text { survey } 2 \text { results with input from policymakers in network. }\end{array}$ \\
$\begin{aligned} \text { - Gradients expanded to } 7 \text { for clarity, preliminary defintions developed for } \\
\text { each category. }\end{aligned}$
\end{tabular}

\begin{tabular}{|c|c|}
\hline Phase 3 & Gradients applied to case studies \\
\hline Objective & - Test and refine gradient framework \\
\hline Action & - Prepare case study protocol based on gradients defined in phase 2 \\
\hline Validation & $\begin{array}{l}\text { - Case study tests: } 4 \text { project cases prepared using case study protocol; In- } \\
\text { person writing workshop tests preliminary gradients by evaluating case } \\
\text { studies. }\end{array}$ \\
\hline Results & $\begin{array}{l}\text { - Refine gradients definitions and add Greenhouse Gas Reduction } \\
\text { (completed February 2018). } \\
\text { - Final test: BVI case study with hosts. }\end{array}$ \\
\hline
\end{tabular}

Figure 2. Phases of the Adaptive Gradient Framework development and testing process.

Given the short answers to the surveys supplemented through discussions during the workshops with SAGE network members and practitioners in these locations, we refined and expanded the gradient scope, as follows. The complexity in responses indicated the initial five gradients were likely not sufficient for a full evaluation. For example, ecology and technical fitness each needed their own category; information as a category was too broad, and it was difficult to evaluate what we do not know; regulatory and political feasibility needed to be separate from issues of justice; benefits 
to local communities were not necessarily the same as a participatory process; a project's ability to contribute to reductions in greenhouse gases was not covered in other items. These findings lead to the eight gradients which make up the Adaptive Gradients Framework: exposure reduction, cost efficiency, institutional capacity, ecological enhancement, adaptation over time, greenhouse gas reduction, participatory process, and social benefits, as defined and further described in the results section.

Discussions among the overall group carefully considered ways to visualize the gradients and the data to support the gradient findings. The importance of clear, communicative visuals is supported by research, which suggests that the abstract nature of climate change, predicted to take place in distant locations in the distant future, contributes to challenges in thinking about, communicating about and caring about the issue $[55,56]$. Beyond knowledge transfer, communicating about climate change to engage the audience in seeking change can be challenging [57]. Network members who work closely with policymakers stressed the importance of a one-page summary with a graphic of findings that can be shown to high-level politicians to generate discussion and support for change. An example of this is shown in Figure 4. Members also highlighted the value of using graphic visualization tools to engage discourse with decision-makers and co-produce understanding of climate change priorities. In the end, we felt that the most visually compelling but easy to produce graphic was the 'spider diagram' shown in Figure 5.

Phase three tested the case study protocol and underlying Adaptive Gradients Framework. The SAGE network developed a case study protocol where data could be organized in a replicable and comparable form, available on our website. The use of a rigorous case study template is a core feature of the process, providing a reproducible path for data collection and analysis. The Network developed four extensive case studies of community coastal interventions: Harlem River Park redevelopment in New York City, Palisados Boardwalk in Jamaica; East Boston coastal protection project in Boston, USA; Ferry Point living shoreline in Maryland. Two of these have already been built (Harlem River, Palisados), while two are in design (East Boston, Ferry Point). One case study (Harlem River) is detailed in Figure 4; for brevity, we could not present the full details of the other case studies here, but all are included on our project website. The data for these case studies was gathered through document analysis, except for Palisados, which we also visited, and organized into the case study protocol. In 2016 and 2017, the SAGE group applied the Adaptive Gradient Framework to these cases in an iterative refinement process. The steps for each included:

1. Lead researcher and assistant use secondary documents to prepare case study while also providing secondary documents to whole panel;

2. Panel members collaboratively discuss the case study to identify and solidify basic information;

3. Individual panel members use the Adaptive Gradients Framework to evaluate the project;

4. Researcher collates the individual evaluations;

5. Full panel discussion of ratings to identify where differences were from varying interpretations of data or gradient framework, and which were basic differences in evaluation;

6. Revisions to case study and framework to reflect uncertainties uncovered in the panel discussion;

7. Reranking of the case study by individual panel members based on new information and collaborative discussion of results.

At the workshop in summer 2017 we undertook proof-of-concept testing by evaluating a site proposal in the British Virgin Islands with government officials from there. By this point, the evaluation was fast-two days in total — the gradient definitions were judged sufficient for rating by the workshop attendees, and the feedback from the client was positive about the Framework's worth. Later, a practitioner's guide was also developed and is available on our website (http: //www.resilient-infrastructure.org/practitioners-guide.html). This provides a very plain language description of the gradients and the process, referring to this paper as the intellectual support for the report. 


\section{Results}

The eight gradients developed using the surveys, workshop, and case study are identified and explained below, including some example considerations that could be asked in a particular evaluation. Each of these provides an important element to include for evaluation of a coastal resiliency project or proposal. Different projects will of course have slightly different questions for each gradient, based on the context of the project and the proposed interventions. The gradients and their relationship to infrastructure projects is summarized in Figure 3. Applying the Adaptive Gradient Framework is further explained following the discussion of the individual gradients.

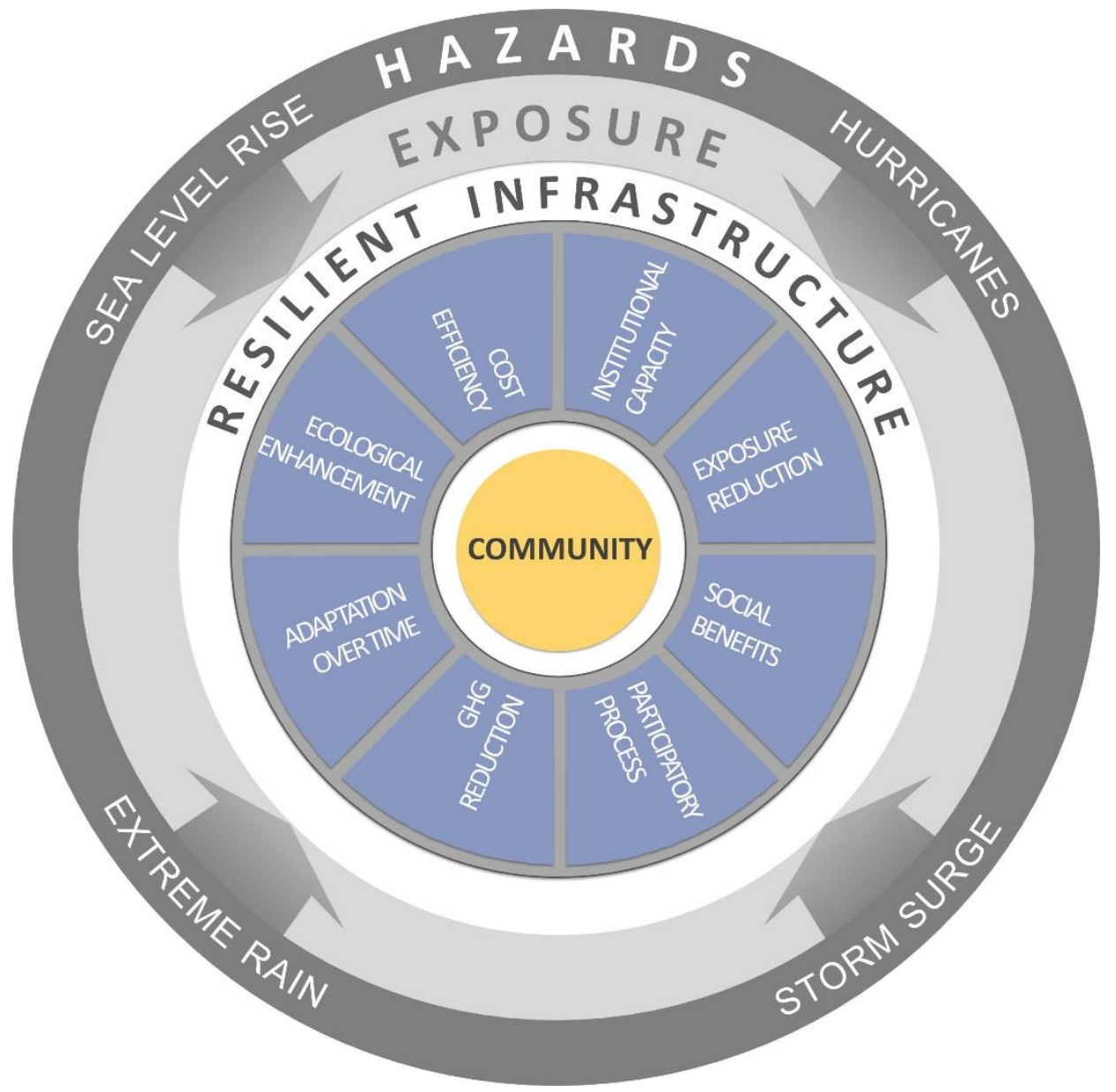

Figure 3. Adaptive Gradients as dimensions of holistic project assessment. Resilient infrastructure protects coastal communities from current and future hazards by reducing exposure while achieving multiple goals. Emerging practices focus on hybrid projects, which may include green (ecosystem based), grey (traditional built infrastructure), and non-structural (zoning, building codes, governance) components. The Adaptive Gradients, shown as the inner wheel, summarize the various dimensions of project success. Outcomes can be measured by contributions to exposure reduction, institutional capacity, cost efficiency, ecological enhancement, adaptation over time, greenhouse gas reduction, participatory process, and social benefits. Investing in the expansion of coastal defenses and incentivizing collaboration between integrated spheres of influence results in better buffering of the community from hazards and uplift to other goals. Evaluation across all these measures will encourage adoption of more complete and community-appropriate resiliency interventions, both currently and as climate changes over time. 


\subsection{Exposure Reduction}

Exposure reduction can be defined as the ability to successfully reduce impacts to at-risk populations or assets when a hazard occurs. Exposure reduction is often the primary goal of infrastructure projects evaluated with existing engineering methods. The amount of exposure reduction will also be relative to the assets (population, buildings, etc.) at risk. Some factors that are particularly important to consider for the Exposure Reduction category include how well the project design will function under different kinds of storm events (such as Nor-Easters or hurricanes). If the project is using built infrastructure such as jetties or seawalls, was consideration given to whether these hardened structures would increase vulnerabilities or other problems such as erosion to adjacent shorelines beyond the immediate project area? Project proposals that are highly rated on this gradient are judged to be technically likely to reduce the impact of hazards.

\subsection{Cost Efficiency}

Actions taken need to demonstrate efficient use of funds and resources, typically measured through standard or extended benefit-cost analysis. It is important to consider both construction and maintenance costs in this category. Some green infrastructure, such as living shorelines, may have lower maintenance costs than grey infrastructure, as the reefs, dunes and marshes have the potential to improve and adapt with time. Green infrastructure is not without maintenance cost, however, as regular monitoring, waste removal and replanting are often required. The incorporation of new and innovative funding practices like climate finance and green financial institutions may increase cost efficiency when compared to traditional loans and financing options. A highly rated project will represent a good/low-cost use of money from sources that suit the local situation.

\subsection{Institutional Capacity}

Projects that are highly rated on this gradient will be a good match to the responsible agency's ability to both fund and maintain the project. The administrative unit's ability to fund the project will impact its implementation, so that available bonding capacity and funding record for that scale of project is important. During the design and construction phase, some factors to consider in this gradient include the experience of the design and construction team(s), their success rate with similar projects, and the diversity of the skills sets on the team(s). Also important to consider are how well the project team is going to work with local, regional and national level governments to facilitate the permitting process, to ensure that project designs will be well-received and are likely to receive regulatory approval. Partnerships with other local companies, NGOs, and academic institutions may be able to provide help with data collection and monitoring or input on design and implementation to facilitate a successful project. Post-construction institutional capacity matters as well. Projects focusing on changing zoning will require the ability of the government to enforce regulations. Green infrastructure, for instance, as a distributed system that may be located on both public and private lands, may require more maintenance staff and administration than a more centralized grey system [58]. Projects focusing on changing zoning will require the ability of the government to enforce regulations. At the same time, a project may assist in building capacity in the agencies responsible. For this gradient we define institutional capacity as the match to governmental or non-governmental strengths, attributes, and resources that reduce impacts, mitigate harm, and ensure future resilience $[59,60]$. This is reflected in the IPCC model, which suggests explicit consideration of socio-economic development pathways and assuring that institutions have the capacity to lead change and respond to risk [61]. A strong match of institutional capacity to the particular challenges of the project being evaluated will bring a high rating on this gradient. 


\subsection{Ecological Enhancement}

Given the high level of biodiversity in coastal areas along with the essential economic resources provided by coastal habitat, projects should be evaluated on how effectively they support or improve the health of local ecosystems. Analysis of this gradient is likely to vary depending on site and regional conditions-rural areas typically offer greater opportunity for ecological preservation due to low development density, while urban areas offer increased potential for innovative or resource-intensive solutions that support remaining coastal habitats. This gradient considers how much ecological "uplift" or improvement a project is going to achieve. If an area has lost beach or wetland habitat, for example, and the project aims to restore as much or more habitat than the amount lost, then this project will have an overall ecological benefit to the area. In order to effectively quantify this benefit, however, it is important to have baseline data on what habitats have been lost or degraded or what habitat features have become degraded (such as decreases in water quality or fishery production or wildlife usage). It may be important for project design teams to include ecological expertise in order to ensure that ecological enhancements occur and to be able to accurately measure these enhancements in comparison to baseline (pre-project) conditions. Additionally, it is important to balance the anticipated long-term ecological benefits with any project impacts to score the overall ecological enhancement of the project. Average rated projects may contribute to sustaining the current ecology, while highly rated projects are expected to contribute to improving local and regional ecologies over the long term.

\subsection{Adaptation over Time}

Solutions should also be effective over time, as social and particularly climatic conditions change. A coastal dune system, for instance, may become more effective at hazard reduction over time as plantings grow, while a seawall may become less effective if sand is scoured from its base over the years. Fitness to projected climate change should also be considered in this gradient. An example of designing for adaptability is to include expected climate change impacts into project plans, such as requiring wider setbacks from the shore to anticipate sea level rise. Well-designed projects may indicate different steps to take over time as conditions change, such accommodating flooding now and retreating from the shoreline as sea levels rise. This can be conceptualized as adaptation pathways [62,63], creating windows of opportunity for matching infrastructural needs to emerging conditions [64]. Adaptation over time does not necessarily mean getting it right the first time, but instead planning via regular monitoring and funding to implement adaptive management as needed to assure that the project functions well despite landscape and socio-economic changes. Plans for monitoring and assessment will also support this gradient, particularly if those plans are binding and properly funded. One important consideration for coastal projects is how much is sea level predicted to rise in the project area over the next 100 years. With these estimates, projects can actually plan to accommodate sea level rise in the design. For example, if marsh habitat is being restored, it is possible to design the elevation of the marsh to include more high marsh species and areas which will eventually become low marsh habitat as sea levels rise. It may also be possible to build into the project design forested or other habitat behind the marsh which will not be marsh in the present conditions but will allow the marsh to migrate inland as sea level rises, such that the total amount of marsh habitat may be able to stay constant despite sea level rise. Consideration of projected population and land use changes is equally important to consider in resilient designs. Thus, a project that explicitly considers climate and socio-economic projections, builds in flexibility or technical capacity to match expected future conditions, and/or enables flexible responses to future changes would receive a high score for adaptation over time.

\subsection{Greenhouse Gas (GhG) Reductions}

Projects can be evaluated on whether they represent more or less embodied energy and/or carbon sequestration. Embodied energy is considered to be the sum total of energy used to extract or mine raw materials, manufacture the raw materials into a product, and transport that product to market, while 
carbon sequestration means the long-term storage of carbon in plants, soils and the like. Typically, concrete has a high embodied energy because it takes a great deal of energy to produce, while living shorelines have low embodied energy and also provide a carbon sink. Plantings in general and coastal wetlands in particular tend to sequester carbon, so project designs that include a substantial amount of living material will usually result in fewer GHG emissions. Projects can also be evaluated on whether they provide long-term energy efficiency, such as including wind turbines in a design. General principles of sustainability, such as use of local or recycled material, can be considered here. This gradient encourages intention in design, so that GHG-reducing strategies are more readily adopted into adaptation practices as they scale upwards over time. Currently, few projects include explicit GhG calculations. Including explicit discussion of GhG in the design or the request for proposals will be contribute to higher ratings on this gradient, as will a lower overall accounting of greenhouse gases associated with the project's construction and operation.

\subsection{Participatory Process}

A participatory process evaluation asks whether the process was transparent, who was included in the decision-making, and whether participants had enough power in the process so that their perspectives made a difference in the final design of the project $[65,66]$. Collaborative processes that engage stakeholders in deliberations are common in participatory processes [67]. Diverse groups should be engaged, including those who may not as readily come to community meetings, and participatory processes should influence the final design of a project [68-70]. Factors to include in evaluation of this gradient are whether multiple mechanisms of engagement were used before, during, and after the project implementation, and to the extent that it can be determined, the level of enthusiasm of the participants and their assessment of the inclusivity of diverse perspectives and consideration of stakeholder goals. A high ranking on this criterion will come from having processes that represent the diverse publics affected by the project, a strong institutional history of engaging diverse publics and directing projects toward achieving expressed stakeholder goals, and a demonstration that the public participation and expressed stakeholder goals changed the design of the project.

\subsection{Social Benefits}

This category addresses both distributive equity and co-benefits. Regardless of participatory process, the actual or anticipated outcomes of a project can contribute to a more equitable and fair balance of benefits and costs and may redress old harms; conversely, projects can have unanticipated negative distribution of consequences, thereby continuing patterns of injustice [39,71]. A particular concern is that climate risk is unevenly distributed, as is the ability to pay for protection and recovery from hazard. Thus, projects that are scored highly in this gradient should benefit community members in historically disadvantaged groups. They may provide indirect social community benefits, such as jobs, recreation opportunities, and healthy accessible environments for a broad population. Specific evaluation of the co-benefits of a project will help to operationalize this issue-are there clear advantages, such as recreational access or improved air quality, for disadvantaged populations? If the investment is likely to increase property values and thus has the potential to bring in new development pressure, has consideration been given to gentrification possibilities? Highly rated projects should appropriately distribute benefits and costs and build a more equitable society through improving the position of those most affected by economic and environmental injustice [72,73].

\subsection{The Framework, Applied to Harlem River Park}

In Figure 4, we demonstrate the application of the adaptive gradients using one case study, Harlem River Park in New York City. This tidal strait was strongly affected by Hurricane Sandy. The project is an early example of integrating green and grey infrastructure to achieve social benefits, and is intended to illuminate the use of the gradients rather than to be a representative coastal case study. Figure 5 presents a diagram of results from the case study. 


\section{Case Study Box: Harlem River Park, New York}

BACKGROUND: The Harlem River Park is a 20-acre linear park on a dense urban riverfront between the busy Harlem River Parkway and the Harlem River between 132nd and 145th streets, on the north-east coastline of Manhattan New York. Harlem River Park serves a dense urban environment with vulnerable populations of which $49 \%$ live in poverty, $10 \%$ are immigrants, $87 \%$ of housing units are rentals, and the median household income is $\$ 31,105$ (U.S Census Bureau, 2016). Risks include flooding from coastal as well as inland sources. Original site conditions include degraded hard shorelines, rip-rap, bulkhead and revetment (HRNEER, 2015).

THE PROJECT: The Harlem River Park revitalization was a three-phase community initiated project aimed to keep the coastline from eroding into the water. Designs were strongly influenced by community activism. Completed in 2009, the $\$ 14.3 \mathrm{M}$ project was funded by a combination of state and city funding and a $\$ 40,000 \mathrm{NY}$ State "Designing the Edge" grant, to research and include habitat-friendly alternatives for water access. This grant enabled the installation of alternatives to standard infrastructure such as porous sea-walls of stacked green walls, flexible gabions, and tide pools. The site also features a focus on native vegetation (HRNEER, 2015).

RESULTS: As a pilot test of the Gradients theory we synthesized existing documents into a case study template which provides both a narrative of the case and data organized to match the gradients. This was sent to a peer panel of seven SAGE experts for evaluation along the gradients from a range of fields including engineering, coastal science, landscape architecture, and planning. Results of the panel are presented in the table below to give a sense of what the pilot study found. Note that the review ratings varied across experts and fields, particularly in areas with less information and/or subjective topics such as equitable outcomes, social capacity or GHG emissions.
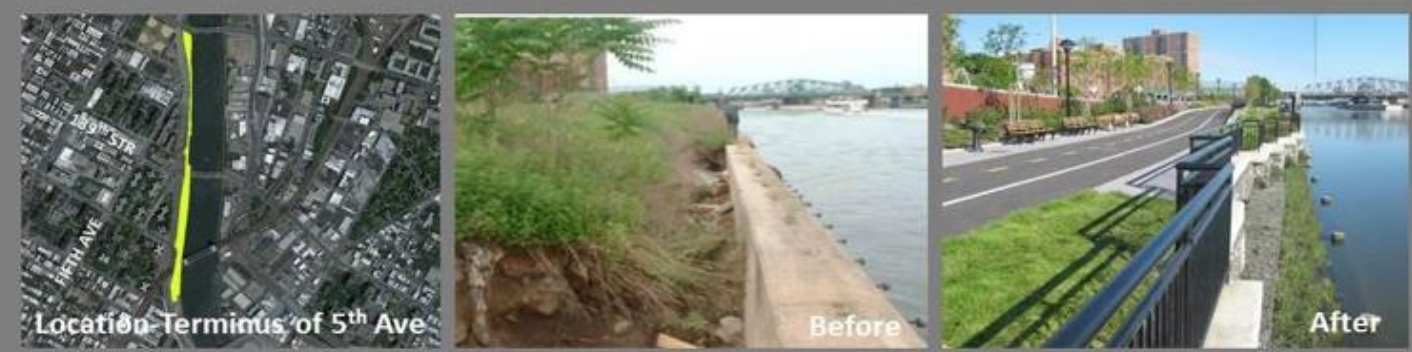

\begin{tabular}{|c|c|c|}
\hline Gradient & Rating & Representative Comments from Different Expert Panel Members \\
\hline Exposure & Medium-low & $\begin{array}{l}\text { The project performed well during Hurricane Sandy. With the project there, less debris was reported } \\
\text { built up after the hurricane. Good spaces for flooding. }\end{array}$ \\
\hline $\begin{array}{l}\text { Institutional } \\
\text { Capacity }\end{array}$ & Medium-high & $\begin{array}{l}\text { Scored high because of grant funding. I thought about the time it took for the project and the steps } \\
\text { taken over the years. }\end{array}$ \\
\hline Cost Efficiency & Medium-high & $\begin{array}{l}\text { I scored this high because I think it cost less than if they had used all grey infrastructure. I think the } \\
\text { maintenance costs/longterm costs are uncertain. }\end{array}$ \\
\hline $\begin{array}{l}\text { Ecological } \\
\text { Enhancement }\end{array}$ & Medium-high & $\begin{array}{l}\text { Vegetation is doing well. They are still figuring out the tree growth/maintenance. I didn't give a } 3 \\
\text { because they used gray (walls) and not a lot of green. }\end{array}$ \\
\hline $\begin{array}{l}\text { Adaptation } \\
\text { over Time }\end{array}$ & Medium & $\begin{array}{l}\text { The project creates tidal pool areas and new volumes of space for water. The vesetation has room to } \\
\text { migrate. If the sea rises will this need to be raised? The project should include an analysis of how it } \\
\text { would hold up with sea level rise. }\end{array}$ \\
\hline $\begin{array}{l}\text { Greenhouse } \\
\text { Gas Reduction }\end{array}$ & Medium-low & $\begin{array}{l}\text { Green space is better than concrete. I would need to know where the materials and vegetation was } \\
\text { grown and what kind of lighting is used. GHG emissions weren't considered in the design process. } \\
\text { Even on small projects, consideration of GHG reduction sets a standard for future. development. }\end{array}$ \\
\hline $\begin{array}{l}\text { Participatory } \\
\text { Process }\end{array}$ & High & $\begin{array}{l}\text { Community was the one who sparked the project and involvement lasted the whole process. The } \\
\text { outcome was changed as a result of community participation. }\end{array}$ \\
\hline $\begin{array}{l}\text { Equitable } \\
\text { Outcomes }\end{array}$ & High & $\begin{array}{l}\text { The neighborhood is relatively poor so investment there brings a good score. I scored it high because } \\
\text { the project improved the overall environmental quality and program options for the area. }\end{array}$ \\
\hline
\end{tabular}

Foot Notess Based on a neighborhood defined as New York County Census tract 210 (Census, 2016) which is a 0.08 Sq mile residential bedroom community with a population of 7,144 . - Greenwalls - sea walls fostering plant growth of various sizes from the "Verdura System," with smail plantable pockets, suitable for vines, grasses and small plants the "Evergreen wall" which is sultable for trees (2). - Gablon - a mesh container filled with heaky materials such as rock, or broken concrete used hi the constructicn of dams, retaining wall, etc (8).

Figure 4. Harlem River case study. This demonstrates the application of the Adaptive Gradients framework, summarizing the findings from the case study template and results from a collaborative peer-review process. 


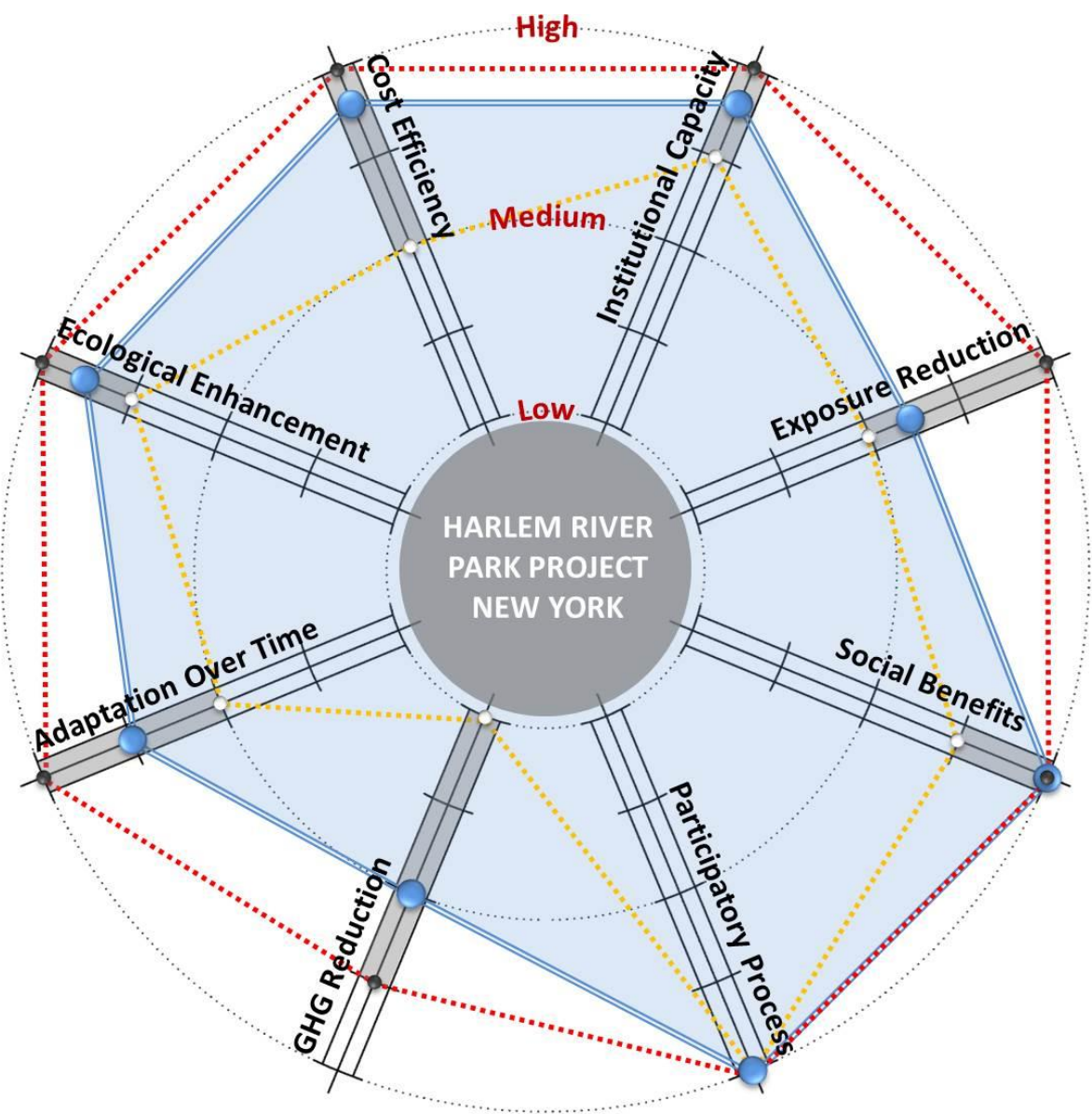

Figure 5. Adaptive Gradients 'Spider Diagram' for the Harlem River Park case study. The relative outcomes for the Harlem River case study are presented along the eight Adaptive Gradients. Blue buttons are the average of the scores, red line shows the maximum for each assessment by individuals on the peer review panels, and yellow the minimum scored outcome by a panel member. The grey bar represents the range of evaluations by the peer panel. Note that evaluation is on a qualitative scale from low to high, rather than numerical, to highlight the important role that judgement plays in each person's score. In this case, we scored a built project to test its actual outcomes.

\section{Discussion and Conclusions}

\subsection{Implementation of the Adaptive Gradients Framework}

The Adaptive Gradients Framework outlines the process an expert review panel can use for a fairly rapid assessment of general project designs. Because it is context specific, it is designed for use on one site at a time, with a host who provides information and can use the results, rather than as a cross-case comparison tool. It will be useful in comparing proposed design packages early in the determination of a project. Analysis through the Adaptive Gradients Framework could also occur in different phases of a project's life, for assessment at intervals along the planning and post-construction timeline for a particular project. Time up front is required for working with the host to gather information and discuss evaluation goals and then for the panel leader to develop a case study following the protocol identified above. At the site, two or three days would likely suffice. It is important that evaluation teams include technical experts from a range of disciplines.

The philosophy behind the scoring process is that knowledge is built collaboratively and through shared development of understanding. Scoring is done by the whole team on all gradient categories to enable discussion about differences in evaluation. The gradient definitions are standard as shown 
above, but their application may vary by individual panel member and individual site, which is why a team approach is necessary. We have found it helpful to have individuals do their own scoring first, and then to discuss those ratings collaboratively to come to a consensus evaluation. Confidence in analyses is increased with multiple iterations of scoring and discussion, helping to create a consistent scale interpretation across disciplines and individuals. Evaluations are descriptive, qualitative, and highly contextual, which is why we believe that non-numeric ranking is best (e.g., 'low' to 'high'). The role of the panel is not to weight the importance of different gradients. Instead, the host can compare results to their own goals and hopes for the project. A low score in some categories may be fine in any particular situation, depending on project goals and stakeholder mission.

Based on our pilot tests of the framework, we envision that an agency or city using the Adaptive Gradients process for a proposed site will proceed as follows:

1. The initiating organization develops basic case study materials organized along gradients, with multiple design options.

2. A panel is chosen, including technical experts plus representatives of a diverse stakeholder group.

3. Pre-scoring is conducted by each member of the panel based on case study materials.

4. Ideally, a site visit with meetings with stakeholders is conducted, but this could be done remotely to save travel time.

5. Panelists discuss their preliminary scoring of the project to highlight differing perspectives; individuals may choose to change their own scoring based on the discussion. Any needed further information is gathered.

6. A final score or score range for each gradient is agreed upon by the group. Where consensus on a score is not reached, the range of scores that individual panel members endorse is included in the final report.

7. Finally, results are placed into the 'spider diagram', a simple visual summary which helps inform policy-makers regarding different policy goals achieved by different proposals.

8. An optional step is for the evaluating team to make recommendations for improving the project based on the analysis done in the steps above.

\subsection{Limitations}

The Adaptive Gradients process framework is designed as a discussion tool, providing a holistic approach to project and proposal evaluation. It does not take the place of a full Environmental Impact Statement, and engineering reviews will still be necessary; in fact, these studies will often form the basis of the information used to do the Gradients analysis. The qualitative rankings are intended to encourage a more interdisciplinary and holistic approach to the decision-making process. The inclusion of qualitative data and more elusive concepts like participation and process is necessary, but is challenging for scoring. The more technical members of each team (e.g., engineers) found qualitative scoring particularly difficult. Similarly, scoring the effectiveness of exposure reduction, for instance, was challenging for social scientists on the team. For both of these cases, collaborative discussion of results led by experts from the appropriate topic area was beneficial. This points to the necessity of cross-disciplinary teams and discussion among members to create a valid outcome. The visual of the gradients can be construed as an argument that each gradient should be equally weighted; rather, each situation will have goals that are most important, and thus gradients will be differentially important in different contexts. Given that we did not want to pre-decide weighting, we felt the even presentation was the most valid, but a local implementation should consciously discuss weighting as part of their analysis. Smaller projects may be constrained in ways that prevent high achievement across all the gradients, while more complex and larger projects or a portfolio of smaller projects may be expected to perform better across all gradients. 


\subsection{Conclusions}

Current and anticipated acute and chronic climate change impacts such as catastrophic and repetitive flooding, sea level rise, and other challenges of climate change along coastlines are resulting in communities becoming more interested in considering new approaches to make their communities more resilient to these threats. However, to help broaden the suite of solutions being considered by communities, and in particular to make those solution options more holistic and inclusive, it is very important that communities consider a wider range of objectives when discussing alternative solutions. This includes considering factors such as social equality or ecological benefits of projects which have typically not been considered when only traditional, built approaches to deal with coastal protection (such as sea walls or levees) are the only available options.

It is essential that research and practice reduce knowledge gaps across disciplines and between academics and policymakers, enabling the adoption of infrastructural solutions that meet a wide range of goals, supporting adaptation decisions that increase resilience to climate change. The Adaptive Gradients Framework proposed here meets these criteria through the explicit qualitative evaluation of eight Adaptive Gradients covering the most relevant socio-economic and biophysical variables in a multi-day, interdisciplinary process. Our case study of Harlem River Park illustrates that the evaluation method can be implemented and led us to design an eight-step process for it to be carried out by an evaluation team. This was supported by testing with three other case studies.

The next step in the research is for our research team to analyze results from implementing the process in a range of settings. To facilitate this process, we are undertaking workshops in Maryland and Puerto Rico to test the process of applying the gradients to project proposals. We also see opportunities for application of the Adaptive Gradients Framework by public and private sector entities with responsibility for choosing coastal resilience interventions and will be seeking feedback about the effectiveness of the framework in these applications. While our focus is coastal projects, there is no reason that the framework needs to be limited to coastal application-holistic solutions are needed in a range of ecological and social settings. We invite others to use the case study template and contribute case study data, and to utilize the framework for collaborative inquiry and decision-making; together, this will build a stronger evidence basis for understanding the goals and mechanisms that lead to more resilient coastal infrastructure. We hope the Adaptive Gradients Framework will become a useful tool for communities to help expand the set of solutions being considered as communities make investments to increase their resilience, and encourage practitioners to download the Practical Guide to Collaborative Project Evaluation (Fricke and Hamin, 2017), available on our website.

The challenges of planning in the face of changing climates is extremely critical in coastal settings, which are already being severely impacted by rising sea levels and extreme weather events. The Adaptive Gradients Framework provides a unique and innovative approach to address these hazards while at the same time strengthening social, economic, and ecological resilience to these challenges. As described by Kelman et al. [74], "those most vulnerable to one challenge tend to be most vulnerable to other challenges", creating a condition of multiple exposure to hazards. The framework allows planners to help vulnerable communities address a range of challenges that are exacerbated by coastal flooding and other disaster events. Building climate change resilience requires addressing the range of issues facing a community beyond engineering and technical solutions, and will assist communities in creating projects with benefits now and into the future.

Supplementary Materials: The following are available on line at http://www.resilient-infrastructure.org/ research.html: 1. Case study template. 2. Practical Guide to Collaborative Project Evaluation. 3. Harlem River case study. 4. Ferry Point Maryland case study. 5. Palisadoes case study. 6. East Boston case study.

Author Contributions: Conceptualization, E.M.H., Y.A., M.D., P.K.J., M.A.K., P.K., T.S., D.D., R.L.R., B.G.M., L.N., J.A.B., A.E.S.-G. and E.A.A.; Data curation, M.A.M. and R.F.; Formal analysis, E.M.H. and M.A.K.; Funding acquisition, E.M.H., M.A.K., T.S. and D.D.; Investigation, M.A.K. and P.K.; Methodology, E.M.H., Y.A., M.D., P.K.J., M.A.K., P.K., T.S., R.L.R. and B.G.M.; Project administration, E.M.H. and R.F.; Resources, Y.A. and M.D.; Supervision, E.M.H. and M.A.K.; Validation, E.M.H., P.K.J., P.K. and R.L.R.; Visualization, Y.A. and M.D.; Writing—original draft, E.M.H., Y.A., M.D., P.K.J., M.A.M., P.K., T.S., D.D., R.L.R., B.G.M. and L.N.; 
Writing—review \& editing, E.M.H., Y.A., M.D., P.K.J., M.A.K., P.K., T.S., D.D., R.L.R., B.G.M., J.A.B., A.E.S.-G. and E.A.A.

Funding: This project is supported by the NSF Research Collaboration Network (RCN): Science, Engineering and Education for Sustainability (SEES), Project title: Sustainable Adaptive Gradients in the Coastal Environment (SAGE): Reconceptualizing the Role of Infrastructure in Resilience Award Number: ICER-1338767 and USDA Massachusetts Agricultural Experiment Station Grant MAS00458. In-kind support was also provided by the Jamaican Government and the University of the West Indies and Pratt University. We gratefully acknowledge the time shared with us by Hurricane Sandy recovery stakeholders in New York City.

Acknowledgments: Other SAGE members contributed to overall development of the project and the ideas and implementation of the gradients concept. These include Allison Baer, Maya Buchanon, Angela Burnett, Barbara Carby, John Charlery, Carter Craft, David Dodman, Fernando Gilbes, Mervin Hastings, Lorna Inniss, Lianna Jarecki, James Kostaris, David Kriebel, Ainsley Lloyd, Kim Penn, Rob Pirani, Tim Randhir, Cynthia Rolli, Steven Scyphers, Kevin Smith, Bhaskar Subramanian, Robert Walker, Dale Webber, Mona Webber, and Robert Weiss.

Conflicts of Interest: The authors declare no conflict of interests. The funding sponsors had no role in the design of the study; in the collection, analyses, or interpretation of data; in the writing of the manuscript; and in the decision to publish the results.

\section{References}

1. Becker, A.; Chase, N.T.L.; Fischer, M.; Schwegler, B.; Mosher, K. A method to estimate climate-critical construction materials applied to seaport protection. Glob. Environ. Chang. 2016, 40, 125-136. [CrossRef]

2. Jongman, B.; Ward, P.J.; Aerts, J.C.J.H. Global exposure to river and coastal flooding: Long term trends and changes. Glob. Environ. Chang. 2012, 22, 823-835. [CrossRef]

3. Mycoo, M. Sustainable tourism, climate change and sea level rise adaptation policies in Barbados. Nat. Resour. Forum 2013, 38, 47-57. [CrossRef]

4. Pelling, M.; Uitto, J.I. Small island developing states: Natural disaster vulnerability and global change. Glob. Environ. Chang. Part B Environ. Hazards 2001, 3, 49-62. [CrossRef]

5. Adger, W.N.; Hughes, T.P.; Folke, C.; Carpenter, S.R.; Rockström, J. Social-ecological resilience to coastal disasters. Science 2005, 309, 1036-1039. [CrossRef] [PubMed]

6. Sandifer, P.A.; Sutton-Grier, A.E.; Ward, B.P. Exploring connections among nature, biodiversity, ecosystem services, and human health and well-being: Opportunities to enhance health and biodiversity conservation. Ecosyst. Serv. 2015, 12, 1-15. [CrossRef]

7. National Oceanic and Atmospheric Administration (NOAA). Guidance for Considering the Use of Living Shorelines; NOAA: Silver Spring, MD, USA, 2015.

8. Sutton-Grier, A.E.; Wowk, K.; Bamford, H. Future of our coasts: The potential for natural and hybrid infrastructure to enhance the resilience of our coastal communities, economies and ecosystems. Environ. Sci. Policy 2015, 51, 137-148. [CrossRef]

9. Chen, L.C.; Liu, Y.C.; Chan, K.C. Integrated Community-Based Disaster Management Program in Taiwan: A Case Study of Shang-An Village. Nat. Hazards 2006, 37, 209-223. [CrossRef]

10. Allen, K.M. Community-based disaster preparedness and climate adaptation: Local capacity-building in the Philippines. Disasters 2006, 30, 81-101. [CrossRef] [PubMed]

11. Muttarak, R.; Pothisiri, W. The role of education on disaster preparedness: Case study of 2012 Indian Ocean earthquakes on Thailand's Andaman Coast. Ecol. Soc. 2013, 18, 1-16. [CrossRef]

12. Lutz, W.; Muttarak, R. Forecasting societies' adaptive capacities through a demographic metabolism model. Nat. Clim. Chang. 2017, 7, 177-184. [CrossRef]

13. Neuman, M. Infiltrating infrastructures: On the nature of networked infrastructure. J. Urban Technol. 2006, 13, 3-31. [CrossRef]

14. Brown, H. Next Generation Infrastructure: Principles for Post-Industrial Public Works; Island Press: Washington, DC, USA, 2014.

15. Klein, R.J.T.; Midgley, G.F.; Preston, B.L.; Alam, M.; Berkhout, F.G.H.; Dow, K.; Shaw, M.R. Adaptation opportunities, constraints, and limits. In Climate Change 2014: Impacts, Adaptation, and Vulnerability. Part A: Global and Sectoral Aspects. Contribution of Working Group II to the Fifth Assessment Report of the Intergovernmental Panel on Climate Change; Field, C.B., Barros, V.R., Dokken, D.J., Mach, K.J., Mastrandrea, M.D., Bilir, T.E., Chatterjee, M., Ebi, K.L., Estrada, Y.O., Genova, R.C., et al., Eds.; Cambridge University Press: Cambridge, UK, 2014; pp. 899-943. 
16. Zaidi, A.; Timothy, D.T.M. Incorporating Natural Infrastructure and Ecosystem Services in Federal Decision-Making. Available online: https://www.whitehouse.gov/blog/2015/10/07/incorporatingnatural-infrastructure-and-ecosystem-services-federal-decision-making (accessed on 20 November 2016).

17. Kenney, M.A.; Hamin, E.M.; Sheahan, T.C. Reconceptualizing the Role of Infrastructure in Resilience. Eos Trans. Am. Geophys. Union 2014, 95, 298. [CrossRef]

18. Nordenson, G.; Seavitt, C. Structures of coastal resilience: Designs for climate change. Soc. Res. 2015, 82, 655-671.

19. Bridges, T.S.; Burks-Copes, K.A.; Bates, M.E.; Collier, Z.A.; Fischenich, J.C.; Piercy, C.D.; Russo, E.J.; Shafer, D.J.; Suedel, B.C.; Gailani, J.Z.; et al. Use of Natural and Nature-Based Features (NNBF) for Coastal Resilience; U.S. Army Engineer Research and Development Center, Environmental Laboratory, Coastal and Hydraulics Laboratory: Vicksburg, MS, USA, 2015.

20. National Research Council; Division on Earth and Life Studies; Board on Atmospheric Sciences and Climate. America's Climate Choices: Panel on Adapting to the Impacts of Climate Change. In Adapting to the Impacts of Climate Change; National Academies Press: Washington, DC, USA, 2011; ISBN 9780309145916.

21. Brown, C.; Ghile, Y.; Laverty, M.; Li, K. Decision scaling: Linking bottom-up vulnerability analysis with climate projections in the water sector. Water Resour. Res. 2012, 48. [CrossRef]

22. IPCC. Climate Change 2014: Synthesis Report. Contribution of Working Groups I, II and III to the Fifth Assessment Report of the Intergovernmental Panel on Climate Change; Core Writing Team, Pachauri, R.K., Meyer, L.A., Eds.; IPCC: Geneva, Switzerland, 2014.

23. IPCC. Climate Change 2014: Impacts, Adaptation, and Vulnerability Summaries, Frequently Asked Questions, and Cross-Chapter Boxes, a Contribution of Working Group II to the Fifth Assessment Report of the Intergovernmental Panel on Climate Change; Field, C.B., Barros, V.R., Dokken, D.J., Mach, K.J., Mastrandrea, M.D., Bilir, T.E., Chatterjee, M., Ebi, K.L., Estrada, Y.O., Genova, R.C., et al., Eds.; World Meteorological Organization: Geneva, Switzerland, 2014.

24. Di Risio, M.; Bruschi, A.; Lisi, I.; Pesarino, V.; Pasquali, D. Comparative Analysis of Coastal Flooding Vulnerability and Hazard Assessment at National Scale. J. Mar. Sci. Eng. 2017, 5, 51. [CrossRef]

25. Silva, S.F.; Martinho, M.; Capitão, R.; Reis, T.; Fortes, C.J.; Ferreira, J.C. An index-based method for coastal-flood risk assessment in low-lying areas (Costa de Caparica, Portugal). Ocean Coast. Manag. 2017, 144, 90-104. [CrossRef]

26. Barnett, J.; O’Neill, S. Maladaptation. Glob. Environ. Chang. 2010, 20, 211-213. [CrossRef]

27. EPA. Guidelines for Preparing Economic Analyses. Available online: https://www.epa.gov/environmentaleconomics/guidelines-preparing-economic-analyses\#download (accessed on 3 October 2017).

28. USGS. Structured Decision Making for Management of Warm-Water Habitat of Manatees. Available online: https:/ / www.usgs.gov/centers/wetland-and-aquatic-research-center-warc/science/structureddecision-making-management-warm?qt-science_center_objects=1\#qt-science_center_objects (accessed on 3 October 2017).

29. Hallegatte, S. Strategies to adapt to an uncertain climate change. Glob. Environ. Chang. 2009, 19, $240-247$. [CrossRef]

30. Ellen, I.G.; Yager, J.; Hanson, M.; Bosher, L. Planning for an Uncertain Future Can Multicriteria Analysis Support Better Decision Making in Climate Planning? J. Plan. Educ. Res. 2016, 36, 349-362. [CrossRef]

31. CEQ. Revised Draft Guidance for Federal Departments and Agencies on Consideration of Greenhouse Gas Emissions and the Effects of Climate Change in NEPA Reviews; Council on Environmental Quality: Washington, DC, USA, 2014; Volume 79.

32. Serban Scrieciu, S.; Belton, V.; Chalabi, Z.; Mechler, R.; Puig, D. Advancing methodological thinking and practice for development-compatible climate policy planning. Mitig. Adapt. Strateg. Glob. Chang. 2014, 19, 261-288. [CrossRef]

33. Jones, L.; Champalle, C.; Chesterman, S.; Cramer, L.; Crane, T.A. Constraining and enabling factors to using long-term climate information in decision-making. Clim. Policy 2017, 17, 551-572. [CrossRef]

34. Matthews, T.; Lo, A.Y.; Byrne, J.A. Reconceptualizing green infrastructure for climate change adaptation: Barriers to adoption and drivers for uptake by spatial planners. Landsc. Urban Plan. 2015, 138, 155-163. [CrossRef]

35. Moser, S.C.; Dilling, L. Creating a Climate for Change: Communicating Climate Change and Facilitating Social Change; Cambridge University Press: Cambridge, UK, 2007; ISBN 9781139461085. 
36. Moser, S.C.; Ekstrom, J.A. A framework to diagnose barriers to climate change adaptation. Proc. Natl. Acad. Sci. USA 2010, 107, 22026-22031. [CrossRef] [PubMed]

37. Mimura, N.; Pulwarty, R.S.; Duc, D.M.; Elshinnawy, I.; Redsteer, M.H.; Huang, H.Q.; Nkem, J.N.; Sanchez Rodriguez, R.A. Adaptation Planning and Implementation. In Climate Change 2014: Impacts, Adaptation, and Vulnerability. Part A: Global and Sectoral Aspects. Contribution of Working Group II to the Fifth Assessment Report of the Intergovernmental Panel on Climate Change; Field, C.B., Barros, V.R., Dokken, D.J., Mach, K.J., Mastrandrea, M.D., Bilir, T.E., Chatterjee, M., Ebi, K.L., Estrada, Y.O., Genova, R.C., et al., Eds.; Cambridge University Press: Cambridge, UK, 2014; pp. 869-898.

38. Hamin, E.M.; Gurran, N.; Emlinger, A.M. Barriers to municipal climate adaptation: Examples from coastal Massachusetts' smaller cities and towns. J. Am. Plan. Assoc. 2014, 80, 110-122. [CrossRef]

39. Shi, L.; Chu, E.; Anguelovski, I.; Aylett, A.; Debats, J.; Goh, K.; Schenk, T.; Seto, K.C.; Dodman, D.; Roberts, D.; et al. Roadmap towards justice in urban climate adaptation research. Nat. Clim. Chang. 2016, 6, 131-137. [CrossRef]

40. Raymond, C.M.; Frantzeskaki, N.; Kabisch, N.; Berry, P.; Breil, M.; Nita, M.R.; Geneletti, D.; Calfapietra, C. A framework for assessing and implementing the co-benefits of nature-based solutions in urban areas. Environ. Sci. Policy 2017, 77, 15-24. [CrossRef]

41. Duguma, L.A.; Minang, P.A.; van Noordwijk, M. Climate Change Mitigation and Adaptation in the Land Use Sector: From Complementarity to Synergy. Environ. Manag. 2014, 54, 420-432. [CrossRef] [PubMed]

42. Younger, M.; Morrow-Almeida, H.R.; Vindigni, S.M.; Dannenberg, A.L. The built environment, climate change, and health: Opportunities for co-benefits. Am. J. Prev. Med. 2008, 35, 517-526. [CrossRef] [PubMed]

43. Hallegatte, S.; Corfee-Morlot, J. Understanding climate change impacts, vulnerability and adaptation at city scale: An introduction. Clim. Chang. 2011, 104, 1-12. [CrossRef]

44. Cutter, S.L.; Finch, C. Temporal and spatial changes in social vulnerability to natural hazards. Proc. Natl. Acad. Sci. USA 2008, 105, 2301-2306. [CrossRef] [PubMed]

45. Heltberg, R.; Siegel, P.B.; Jorgensen, S.L. Addressing human vulnerability to climate change: Toward a "no-regrets" approach. Glob. Environ. Chang. 2009, 19, 89-99. [CrossRef]

46. Smit, B.; Wandel, J. Adaptation, adaptive capacity and vulnerability. Glob. Environ. Chang. 2006, 16, $282-292$. [CrossRef]

47. Cutter, S.L.; Boruff, B.J.; Shirley, W.L. Social vulnerability to environmental hazards. Soc. Sci. Q. 2003, 84, 242-261. [CrossRef]

48. Cutter, S.L.; Barnes, L.; Berry, M.; Burton, C.; Evans, E.; Tate, E.; Webb, J. A place-based model for understanding community resilience to natural disasters. Glob. Environ. Chang. 2008, 18, 598-606. [CrossRef]

49. Moser, S.C.; Boykoff, M.T. Successful Adaptation to Climate Change: Linking Science and Policy in a Rapidly Changing World; Routledge: Abingdon-on-Thames, UK, 2013; ISBN 9781135071301.

50. Kenney, M.A.; Janetos, A.C.; Lough, G.C. Building an integrated U.S. National Climate Indicators System. Clim. Chang. 2016, 135, 85-96. [CrossRef]

51. Ahern, J. From fail-safe to safe-to-fail: Sustainability and resilience in the new urban world. Landsc. Urban Plan. 2011, 100, 341-343. [CrossRef]

52. Mendoza, G.A.; Martins, H. Multi-criteria decision analysis in natural resource management: A critical review of methods and new modelling paradigms. For. Ecol. Manag. 2006, 230, 1-22. [CrossRef]

53. Bierbaum, R.; Smith, J.B.; Lee, A.; Blair, M.; Carter, L.; Chapin, F.S.; Fleming, P.; Ruffo, S.; Stults, M.; McNeeley, S.; et al. A comprehensive review of climate adaptation in the United States: More than before, but less than needed. Mitig. Adapt. Strateg. Glob. Chang. 2013, 18, 361-406. [CrossRef]

54. McDaniels, T.; Chang, S.; Cole, D.; Mikawoz, J.; Longstaff, H. Fostering resilience to extreme events within infrastructure systems: Characterizing decision contexts for mitigation and adaptation. Glob. Environ. Chang. 2008, 18, 310-318. [CrossRef]

55. Scannell, L.; Gifford, R. Personally relevant climate change: The role of place attachment and local versus global message framing in engagement. Environ. Behav. 2013, 45, 60-85. [CrossRef]

56. Boulton, E. Climate change as a "hyperobject": A critical review of Timothy Morton's reframing narrative. Wiley Interdiscip. Rev. Clim. Chang. 2016, 7, 772-785. [CrossRef]

57. Gifford, R. The dragons of inaction: Psychological barriers that limit climate change mitigation and adaptation. Am. Psychol. 2011, 66, 290-302. [CrossRef] [PubMed] 
58. Keeley, M.; Koburger, A.; Dolowitz, D.P.; Medearis, D.; Nickel, D.; Shuster, W. Perspectives on the Use of Green Infrastructure for Stormwater Management in Cleveland and Milwaukee. Environ. Manag. 2013, 51, 1093-1108. [CrossRef] [PubMed]

59. Aldrich, D.P.; Meyer, M.A. Social Capital and Community Resilience. Am. Behav. Sci. 2015, 59, $254-269$. [CrossRef]

60. Smith, J.B.; Klein, R.J.T.; Huq, S. Climate Change, Adaptive Capacity and Development; Imperial College Press: London, UK, 2003.

61. IPCC. Managing the Risks of Extreme Events and Disasters to Advance Climate Change Adaptation. A Special Report of Working Groups I and II of the Intergovernmental Panel on Climate Change; Field, C.B., Barros, V., Stocker, T.F., Qin, D., Dokken, D.J., Ebi, K.L., Mastrandrea, M.D., Mach, K.J., Plattner, G.-K., Allen, S.K., et al., Eds.; IPCC: Cambridge, UK; New York, NY, USA, 2012.

62. Haasnoot, M.; Kwakkel, J.H.; Walker, W.E.; ter Maat, J. Dynamic adaptive policy pathways: A method for crafting robust decisions for a deeply uncertain world. Glob. Environ. Chang. 2013, 23, 485-498. [CrossRef]

63. Rosenzweig, C.; Solecki, W. Hurricane Sandy and adaptation pathways in New York: Lessons from a first-responder city. Glob. Environ. Chang. 2014, 28, 395-408. [CrossRef]

64. Abunnasr, Y.; Hamin, E.M.; Brabec, E. Windows of opportunity: Addressing climate uncertainty through adaptation plan implementation. J. Environ. Plan. Manag. 2015, 58, 135-155. [CrossRef]

65. Arnstein, S.R. A Ladder of Citizen Participation. J. Am. Inst. Plan. 1969, 35, 216-224. [CrossRef]

66. Collins, K.; Ison, R. Jumping off Arnstein's ladder: Social learning as a new policy paradigm for climate change adaptation. Environ. Policy Gov. 2009, 19, 358-373. [CrossRef]

67. Innes, J.E.; Booher, D.E. Planning with Complexity: An Introduction to Collaborative Rationality for Public Policy; Routledge: Abingdon-on-Thames, UK, 2010; ISBN 9781135194277.

68. Meadow, A.M.; Ferguson, D.B.; Guido, Z.; Horangic, A.; Owen, G.; Wall, T. Moving toward the Deliberate Coproduction of Climate Science Knowledge. Weather Clim. Soc. 2015, 7, 179-191. [CrossRef]

69. Head, B.W. Community Engagement: Participation on Whose Terms? Aust. J. Political Sci. 2007, 42, 441-454. [CrossRef]

70. Cornwall, A. Unpacking "Participation": Models, meanings and practices. Community Dev. J. 2008, 43, 269-283. [CrossRef]

71. Adger, W.N. Place, well-being, and fairness shape priorities for adaptation to climate change. Glob. Environ. Chang. 2016, 38, A1-A3. [CrossRef]

72. Goodin, R.E. Utilitarianism as a Public Philosophy; Cambridge University Press: Cambridge, UK, 1995.

73. Rawls, J. A Theory of Justice; Harvard University Press: Cambridge, MA, USA, 2009.

74. Kelman, I.; Gaillard, J.C.; Lewis, J.; Mercer, J. Learning from the history of disaster vulnerability and resilience research and practice for climate change. Nat. Hazards 2016, 82 (Suppl. 1), S129-S143. [CrossRef] 